\title{
Limited effect of a highway barrier on the genetic structure of a gypsum soil specialist
}

\author{
Irene Martín-Rodríguez ${ }^{\text {Corresp., } 1}$, Adrián Escudero ${ }^{1}$, Alfredo García-Fernández ${ }^{1}$ \\ 1 Área de Biodiversidad y Conservación. Departamento de Biología y Geología, Física y Química Orgánica, Universidad Rey Juan Carlos, Móstoles, Madrid, \\ Spain \\ Corresponding Author: Irene Martín-Rodríguez \\ Email address: irene.martin@urjc.es
}

Background. Gypsum ecosystems are edaphic islands surrounded by a matrix that is inhospitable to gypsum soil plant specialists. These naturally fragmented landscapes are currently exacerbated due to man-made disturbances, jeopardising their valuable biodiversity. Concomitant action of other fragmentation drivers such as linear infrastructures may increase the already high threat to these specialists. Although some evidence suggest that gypsophytes are not evolutive dead-ends and can respond to fragmentation by means of phenotypic plasticity, the simultaneous action of barriers to genetic flow can pose a severe hazard to their viability. Here, we evaluated the effect on the genetic flow and diversity of a highway with heavy traffic in the species Lepidium subulatum, a dominant Iberian shrubby gypsophyte. Methods. We tested the possible existence of bottlenecks, and estimated the genetic diversity, gene flow and genetic structure in the remnant populations, exploring in detail the effect of a highway as a possible barrier. Results. Results showed variability in genetic diversity, migrants and structure. The highway had a low impact on the species since populations can retain high levels of genetic diversity and genetic parameter, like $F_{S T}$ and $F_{I S}$, did not seem to be affected. The presence of some level of genetic flow in both sides along the highway could explain the relatively high genetic diversity in the habitat remnants. Discussion. Natural fragmentation and their exacerbation by agriculture and linear infrastructures seem to be negligible for this species and do not limit its viability. The biological features, demographic dynamics and population structures of gypsum species seem to be a valuable, adaptive pre-requisite to be a soil specialist and to maintain its competitiveness with other species in such adverse stressful conditions. 


\section{Limited effect of a highway barrier on the genetic} 2 structure of a gypsum soil specialist

3

4 Short tittle: Highway effects over gypsophytes genetics

5

6 Irene Martín-Rodríguez ${ }^{1}$, Adrián Escudero ${ }^{1}$, Alfredo García-Fernández ${ }^{1}$

$7{ }^{1}$ Área de Biodiversidad y Conservación. Departamento de Biología y Geología, Física y

8 Química Orgánica. Universidad Rey Juan Carlos. Calle Tulipán s/n Móstoles, Madrid, Spain. 9

Corresponding autor:

11 Irene Martín-Rodríguez.

12 Calle Tulipán, Móstoles, Madrid, E-28932, Spain

13 Email address: irene.martin@urjc.es

14

ORCID: Irene Martín-Rodríguez: 0000-0003-2266-2745; Alfredo García-Fernández: 0000-0002- 


\section{Abstract}

Background. Gypsum ecosystems are edaphic islands surrounded by a matrix that is inhospitable to gypsum soil plant specialists. These naturally fragmented landscapes are currently exacerbated due to man-made disturbances, jeopardising their valuable biodiversity. Concomitant action of other fragmentation drivers such as linear infrastructures may increase the already high threat to these specialists. Although some evidence suggest that gypsophytes are not evolutive dead-ends and can respond to fragmentation by means of phenotypic plasticity, the simultaneous action of barriers to genetic flow can pose a severe hazard to their viability. Here, we evaluated the effect on the genetic flow and diversity of a highway with heavy traffic in the species Lepidium subulatum, a dominant Iberian shrubby gypsophyte.

Methods. We used eight nuclear microsatellites for testing the possible existence of bottlenecks, and estimating the genetic diversity, gene flow and genetic structure in the remnant populations, exploring in detail the effect of a highway as a possible barrier.

Results. Results showed variability in genetic diversity, migrants and structure. The highway had a low impact on the species since populations can retain high levels of genetic diversity and genetic parameter, like $F_{S T}$ and $F_{I S}$, did not seem to be affected. The presence of some level of genetic flow in both sides along the highway could explain the relatively high genetic diversity in the habitat remnants.

Discussion. Natural fragmentation and their exacerbation by agriculture and linear infrastructures seem to be negligible for this species and do not limit its viability. The biological features, demographic dynamics and population structures of gypsum species seem to be a valuable, adaptive pre-requisite to be a soil specialist and to maintain its competitiveness with other species in such adverse stressful conditions.

\section{Introduction}

Fragmentation is known as a pervasive anthropogenic process in which habitat loss triggers the division of the available habitat into patches, creating small, isolated and low quality fragments which are subject to the action of other concomitant negative biological processes (e.g. edge effects, decreased abundance and richness, and increased mortality rate, among others, Boulinier et al., 2001; Fahrig, 2002; 2003). Connectivity is a critical parameter for long-term demographic viability in fragmented landscapes, conveying information about the species' movement and genetic flow between suitable remnants (Nogués \& Cabarga-Varona, 2014). It is usually measured by indirect surrogates, such as the number of habitat patches in a given area, the patch size or the nearest neighbour distance. In addition, some estimates of plant and population performance are usually considered when fragmentation effects want to be isolated (Fahrig, 2003; Zhou et al., 2016). Although only a minimal set of studies have used molecular markers to evaluate the connection between fragments (Martínez-Nieto et al., 2012; GómezFernández, Alcocer \& Matesanz, 2016), there is no doubt that fragmentation profoundly affects the gene flow between them and, also, the performance and viability of plant populations within each habitat remnant (see Fahrig, 2003). Many studies have shown that the population's 
permanence and viability on one of these islands depends on the fragmentation process itself and, moreover, on dispersal ability which is critical for connecting patches of suitable habitat (Bascompte, Possingham \& Roughgarden, 2002).

Linear infrastructure is one of the main causes of habitat fragmentation (Nogués \& Cabarga-Varona, 2014), especially in high-income countries. Aside from the negative effects of fragmentation (Benítez-López, Alkemade \& Verweij, 2010; Karlson, Mörtberg \& Balfors, 2014), linear infrastructure can also trigger an additional barrier effect, which can modify genetic flow among populations (Ament et al. 2008), increasing invasive species (Forman \& Alexander, 1998; Boarman \& Sazaki, 2006) or increasing human access (Benítez-López, Alkemade \& Verweij, 2010; Clauzel et al., 2015). On the other hand, some species are favoured by infrastructure (Karlson, Mörtberg \& Balfors, 2014) because they are able to colonise new habitats created by the infrastructure, such as embankments (Forman \& Alexander, 1998; Arenas et al., 2015), especially in areas with extensive crops where the availability of habitat remnants is scarce (Coffin, 2007). Adjacent spaces to these roads are also used by livestock animals (Coffin, 2007), which play an important role in seed dispersal, especially along the infrastructure (Arenas et al., 2017).

Landscape genetics is an emerging discipline devoted to explaining how the genetic variability and the gene flow among populations could be affected by landscape conditions, including habitat loss and fragmentation (Adams \& Brug, 2015; Kierepka \& Latch, 2015; Suni \& Witheley, 2015). It is experiencing exponential growth, exploring patterns in different species (Segelbacher et al., 2010; Manel \& Holderegger, 2013).

Gypsum soils are one of the most diverse and threatened habitats of arid and semi-arid climates worldwide (Escudero et al., 2015), giving shelter to a very specialised flora with a high number of endemics, many of them highly endangered and narrowly distributed (Romão \& Escudero, 2005; Martínez-Hernández et al., 2011). These habitats are natural island-like scenarios since they are formed of gypsum outcrops immersed in soils of another nature, creating outcrops surrounded by a matrix inhospitable to these specialists (Escudero et al., 2015; Matesanz et al., 2018). Nonetheless, anthropic fragmentation due to agriculture intensification is exacerbating this natural insularity and posing, in many cases, extreme risk to most of these diverse hotspots (Mota et al., 2004; Escudero et al., 2015). A recent work suggested that some of these soil specialists are resilient enough to face this anthropogenic fragmentation, probably due to an evolutionary history in which natural fragmentation was the norm (Matesanz et al., 2017; 2018), therefore they are adapted to fragmentation: high evolutionary potential, phenotypic plasticity, generalist outcrossing, potent soil seed bank, etc. (Matesanz et al., 2017; 2018). However, the over-imposition of an additional barrier for dispersers and pollinators could be affecting the gene flow between the habitat remnants, limiting the long-term viability of these soil specialists.

Here, we performed a study of landscape genetics in a widely distributed and abundant Iberian gypsophile, Lepidium subulatum (Eugenio et al., 2012). This is an exceptional plant model for evaluating the effect of linear infrastructure on its gene flow due to several previous 
117 studies of the species. It is a common plant in gypsum soils communities, with specific

118

119

120

121

122

123

124

125

126

127

128

129

130

131

132

133

134

135

136

137

138

139

140

141

142

143

144

145

146

147

148

149

150

151

152

153

154

155 molecular markers available, demographic populations approaches, etc. Previous works clearly indicated this species is flexible enough to guarantee genetic connection between gypsum islands, even in landscapes subject to severe agricultural intensification (Gómez-Fernández, Alcocer \& Matesanz, 2016; Matesanz et al., 2017; 2018). Therefore, we could evaluate the effect of the highway on the gene flow without the spatial structure of patches affecting our results. This was done over a substantial area in which remnants of gypsum habitats are dissected by a busy highway. Our working hypothesis is that this barrier may affect genetic flow not only between the two sides of the highway but also along the highway. For this, we used specific genetic markers (Martínez-Nieto et al., 2012) and characterised in spatial terms all the patches in this area. More specifically, we want to answer the following questions: (i) is there an effect of the highway apparent in the genetic diversity of Lepidium subulatum' populations?; (ii) are patches isolated according to the distance between them? If so, is the road enhancing the fragmentation or the connectivity between patches? and, finally, (iii) are genetic parameters, environmental variables and landscape features related and/or modified by the presence of the highway?

\section{Materials and methods Study species}

Lepidium subulatum L. (Brassicaceae) in an endemic chamaephyte of the Iberian Peninsula with a few populations in North Africa, specialist of gypsum soils (Hernández Bermejo \& Clemente, 1993). It is a perennial shrub (up to 26 years; Eugenio et al., 2012), 20-60 $\mathrm{cm}$ in height (Palacio \& Montserrat-Martí, 2005; Romão \& Escudero, 2005). It is a generally entomophilous and primarily self-incompatible species (Matesanz et al., 2015). The species is diploid with eight chromosome pairs (2n=16; Hernández Bermejo \& Clemente, 1993).

Outcrossing and atelechorous seed dispersal with seeds covered by a mucilage able to anchor the seeds in the vicinity of mother plants surely affects its ability to connect habitat remnants (Gómez-Fernández, Alcocer \& Matesanz, 2016).

\section{Study area}

The area is a homogeneous landscape at the south-east corner of Madrid, central Spain. It is characterised by the presence of fragments of gypsum vegetation, surrounded by an intensively managed matrix of dry, extensive crops (coordinates in URM ETRS89 30N: the centroid of the most north-westerly population (Pop 13) 4438624, 489512; the most south-easterly population (Pop 12) 4432335, 495277). The climate is arid, with an annual average temperature and rainfall of $13.8^{\circ} \mathrm{C}$ and $440 \mathrm{~mm}$, respectively and almost no rainfalls during the summer (Meteorological Station of Arganda del Rey, 459310, 4462676; 38-48 km away from the study area). The area is dissected northwest to south east for more than $15 \mathrm{kms}$ by the A-3 highway, which has operated for more 35 years in its present configuration (Madrid-Valencia, a motorway with four traffic 
156

157

158

159

160

161

162

163

164

165

166

167

168

169

170

171

172

173

174

175

176

177

178

179

180

181

182

183

184

185

186

187

188

189

190

191

192

193

194

195

lanes and a width of $25 \mathrm{~m}$; Boletín Oficial del Estado, 2016), dividing the area into two similar halves.

We chose 24 populations or patches distributed at both sides of the A-3 motorway, selecting the same number of populations on each side of the area in a strio of $3 \mathrm{kms}$ from the highway (Fig. 1) and maximising the range of fragment sizes and connectivity. Populations were selected from the kilometre point 65 to 75 along the highway. In each gypsum patch we collected samples from 8-20 individuals (average 16.2 \pm 4.2 individuals) for DNA extraction (Table S1). We calculated L. subulatum population density as the number of intersected individuals in a transect of $250 \mathrm{~m}$ across the patch. Remnants with insufficient number of individuals were discarded to avoid confounding effects on flow arising from small population sizes. For each remnant patch, the following variables were also estimated: fragment area, patch perimeter and distance to the highway from the patch's edge and from the centroid using ArcGis 10.8 (ESRI 2020). In addition, we calculated the connectivity among patches with Tremlová \& Münzbergová's connectivity index (Tremlová \& Münzbergová, 2007). This was done taking into consideration all the remnants present in the area (see Arenas et al., 2017 for details).

In order to connect genetic parameters with the physical-chemical characterisation of each patch (remnant's quality), we collected two soils samplings per patch with a core ten centimetres deep and six centimetres in diameter. Samples were analysed for total amount of nitrogen $(\mathrm{N})$, phosphorous $(\mathrm{P})$, potassium $(\mathrm{K})$, organic carbon, $\mathrm{pH}$, conductivity and glucosidase and phosphatase's activity in Nutrilab/URJC (https://nutrilab-urjc.es/). We subjected the samples to a sulphuric acid digest and then used an SKALAR San ${ }^{++}$Analyser to estimate $\mathrm{N}$ and $\mathrm{P}$ (Skalar, Breda, Nertherland; Maestre \& Puche, 2009). For K, samples were shaken with distilled water in the ratio 1:5 prior to digestion (Maestre \& Puche, 2009). We used the Walkley-Black method (Gelman, Binstock \& Halicz, 2012; Hiromi et al., 2014) for estimating organic C. We measured $\mathrm{pH}$ and conductivity using a solution 1:2.5 (weight:volume). We used the protocols described in Maestre \& Puche (2009) to measure glucosidase and phosphatase activity.

\section{DNA extraction, amplification and sequencing}

Material collection was approved by the Consejería de Educación e Investigación de la Comunidad de Madrid (REMEDINAL-TE CM, P2018/EMT-4338). The genetic study was performed with eight specific microsatellites markers: Lsub01, Lsub02, Lsub03, Lsub04, Lsub05, Lsub07, Lsub08, Lsub12 (Martínez-Nieto et al., 2012). DNA was extracted from $60 \mathrm{mg}$ of dried young leaf tissues using the SpeedTools Plant Extraction kit (Biotools, Madrid, Spain). We amplified individually each microsatellite using Polymerase Chain Reactions, mixing $14.2 \mu \mathrm{l}$ of milli-Q water, $2 \mu \mathrm{l}$ of T10X buffer with $\mathrm{MgCl}_{2}, 0.8 \mu \mathrm{l}$ of dNTP mix, 0.5 pmol of each primer (forward labelled with fluorescence dye and reverse) $1 \mathrm{U}$ of Taq-polymerase (Biotools, Madrid, Spain) and $1.2 \mu$ of DNA. The thermocycler's protocol was: 4 min at $95^{\circ} \mathrm{C}$, followed by 30 cycles of $45 \mathrm{~s}$ at $95^{\circ} \mathrm{C}, 45 \mathrm{~s}$ at $51^{\circ} \mathrm{C}$ (annealing temperature) and $1 \mathrm{~min}$ at $72^{\circ} \mathrm{C}$, followed by a final step of $7 \mathrm{~min}$ at $72^{\circ} \mathrm{C}$. PCRs were checked using electrophoresis in agarose gel pre-stained with Gel Red (Biotium, Hayward, USA). Lastly, the amplified fragments were analysed with an 
196

197

198

199

200

201

202

203

204

205

206

207

208

209

210

211

212

213

214

215

216

217

218

219

220

221

222

223

224

225

226

227

228

229

230

231

232

233

234

235

ABI 3730XL sequencer (Applied Biosystems, Foster City, USA) of the Unidad de Genómica (Universidad Complutense, Madrid, Spain).

\section{Statistical analysis}

We tested the Hardy-Weinberg equilibrium with Genepop 4.7 (Raymond \& Rousset, 1995; Rousset, 2008) and the presence of null alleles by MicroChecker 2.2.3 (Van Oosterhout et al., 2004). We also calculated the allelic richness per population/patch, the total number of private alleles, the expected and observed heterozygosity $\left(H_{E}\right.$ and $\left.H_{O}\right)$, the inbreeding coefficient $(F)$, and the number of migratory individuals $(\mathrm{Nm})$, using GenAlEx 6.5 software (Peakall \& Smouse, 2006). Complementarily, migration rates or number of migrants were estimated with BayesAss 3.04 (Wilson \&Rannala, 2003) and Migrate 4.4.3 (Beerli , 2009), to estimate recent or past gene flow rates respectively. We calculated the $F_{S T}$ with a null alleles correction with FreeNA (Chapuis \& Estoup, 2007; Chapuis et al., 2008). Due to the different numbers of individuals sampled in each population, the allelic richness was calculated by rarefaction analysis using HPRare v June-6-2006 programs (Kalinowski, 2005). To evaluate the existence of any genetic bottleneck, we used the Wilcoxon test in Bottleneck v.1.2.02 software (Cornuet \& Luikart, 1996a). This measures deviations in heterozygosity and deficiencies in allelic richness. It takes into consideration that, when a bottleneck is produced, the effective population size drops, triggering a decrease in the allelic number that exceeds the effects of heterozygosity (Cornuet \& Luikart, 1996b). We run three different mutation models: infinite allele model (I.A.M.), step wise-mutation model (S.M.M.) and intermediate two-phase mutation model (T.P.M.). We used the parameters by default for T.P.M. (70\% of proportion of S.M.M. and 30\% of variance). For each model, we performed 2000 iterations. We also evaluated whether any of the genetic parameters (i.e. allelic richness, private alleles, $H_{O}, H_{E}, F, F_{S T}$ average or Nm average) were affected by some soil variables (i.e. N, P, K organic carbon, $\mathrm{pH}$, conductivity, phosphatase and glucosidase) which are surrogates of habitat quality, connectivity $\left(C_{i}\right)$, other landscape variables (fragment size, perimeter of the remnant and minimum distance to highway) and population density. For this, we utilised General Linear Models (GLMs) using R v.3.3.0 ( $R$ Core Team, 2016); in which we tested a model with all independent variables but without interactions among predictors. P-values were corrected using Bonferroni's adjust to avoid the multiple comparison effect.

We studied the genetic structure of the 24 populations using a Bayesian clustering method with STRUCTURE v.2.3.4 with prior information on population membership. Ten independent runs were carried out for each $K$ value (i.e. number of potential clusters, ranging from 1 to 27), each one with a burn-in period of $10^{5}$ iterations followed by $10^{6} \mathrm{MCMC}$ iterations and $10^{4}$ thinning. Analyses were developed with allelic correlation frequencies and genetic admixture. According to the different population sampled, we used the STRUCTURESelector ( $L i \&$ Liu, 2018) module to obtain K values. We considered the Evanno method (Evanno, Regnaut \& Goudet, 2005), together with MedMeaK (median of means), MedMedK (median of medians), MaxMeaK (maximum of means) and MaxMedK (Maximum of medians) proposed by Puechmaille (2016) with a threshold value $=0.6$, to discard spurious clusters and detect potential 
236

237

238

239

240

241

242

243

244

245

246

247

248

249

250

251

252

253

254

255

256

257

258

259

260

261

262

263

264

265

266

267

268

269

270

271

272

273

274

substructure. Also, to complement the STRUCTURE analysis (Puechmaille, 2016; Janes et al., 2017), we performed a spatial Principal Components Analysys by adegenet v. 2.2.1 package in $\mathrm{R}$ (Jombart, 2008; Jombart \& Ahmed, 2011) to evaluate the global and local spatial structure.

To evaluate the effect of the highway as a modifier agent of the genetic landscape, genetic diversity and differentiation was estimated, considering the two sides of the motorway (NE versus SW population groups) separately. In addition, an AMOVA (Analysis of MOlecular VAriance), performed by GenAlEx 6.5 software (Peakall \& Smouse, 2006), was used to estimate and evaluate the distribution of the percentage of intra- and interpopulation variability, including both highway sides as different regions. These results also complemented the genetic structure analyses (see below). To test if the highway triggered a barrier effect between both sides, we calculated the average of $F_{S T}$ of one side (northeast or southwest) with each population of the other highway side to observe if the value was significantly different with the $F_{S T}$ average of the first side. We also analysed the effect of highway and geographic distance between pairs of populations using Generalised Least Squares (GLS) models with the nlme and corMLPE packages (Pinheiro et al., 2018; Pope, 2019). The corMLPE package constructs regressions using distance matrices with non-linearity and random effects. In this case, we selected two populations and used as independent variables the side of highway (binary variable: $0=$ same side of the motorway; $1=$ different side) and the distance between populations. We selected the best model using AIC, using $F_{S T}$ as the dependent variable and geographic distance, highway side and their interactions as the independent variable.

\section{Results}

\section{Patch genetic characterisation.}

None of populations in remnants were in $\mathrm{H}-\mathrm{W}$ equilibrium, except population 13 and 14 (Table S1). Some microsatellites could present some null alleles (Table S1). We found an average allelic richness per patch/population of $7.3 \pm 1.3$ alleles. Population 21 presented the highest value $(n=10.4 \pm 1.8)$ and population 4 , the lowest $(n=4.6 \pm 1.2)$ (Tables 1 and $S 1)$. When the average number of alleles was rarefied, the average richness decreased to $4.9 \pm 1.1$ (Table 1). In this case, population 4 continued as the poorest $(n=3.8 \pm 0.9)$, whereas population 12 was the richest $(n=8.3 \pm 0.6)$ (Tables 1 and $\mathrm{S} 1)$. The total number of private alleles was 35 , but several populations did not have any (populations 1, 8, 12, 15, 16, 17, 18, 19, 20) (Table 1 and S1). In contrast to allelic richness, population 4 had the highest number of private alleles $(n=5)($ Table $\mathrm{S} 1$ ). Expected heterozygosity was higher than observed in all populations (average $H_{E}=$ $0.7588 \pm 0.0$ and average $H_{O}=0.6507 \pm 0.1$, respectively). Population 21 showed the highest expected heterozygosity, while population 4 had the lowest $\left(H_{E}=0.8 \pm 0.0\right.$ and $H_{E}=0.7 \pm 0.1$, respectively) (Table S1). Nevertheless, the population with the highest observed heterozygosity was population 5; and the lowest, population $12\left(H_{O}=0.8 \pm 0.2\right.$ and $H_{O}=0.5 \pm 0.3$, respectively) (Table S1). Finally, the average inbreeding coefficient $(F)$ was $0.1 \pm 0.1$, with great variation between populations. Population 5 had the lowest inbreeding coefficient, showing a patent 
275

276

277

278

279

280

281

282

283

284

285

286

287

288

289

290

291

292

293

294

295

296

297

298

299

300

301

302

303

304

305

306

307

308

309

310

311

312

313

314

heterozygosity excess $(F=0.0 \pm 0.2)$; meanwhile, population 12 had the highest coefficient $(F=$ $0.3 \pm 0.3$ ) (Table S1). The presence of bottlenecks was detected for all populations. (Table S3).

\section{Genetic differentiation and migrants: Highway effect.}

The average number of migratory individuals between population/patches $(\mathrm{Nm})$ was 4.02 (Table 1). Population 22 had the highest number of migratory individuals $(N m=5.6)$; and population 12 , the lowest $(N m=1.4)$ (Table $\mathrm{S} 1)$. Genetic differentiation based on $F_{S T}$ coefficients, showed an average value between population pairs of 0.1 , suggesting moderate genetic differentiation across the study area (Table S1) suggesting certain degree of isolation.

When comparing the populations located on either side of the highway (see Figure 1), there were significant differences in the number of private alleles and number of migratory individuals. In the case of private alleles, the populations of the SW side presented a higher number ( $n=22$ and $n=13$, respectively) (Table 1 ), while the NE half had a higher number of migratory individuals ( $N m=5.1$ and $N m=2.8$, respectively). The NE population with the highest number of migratory individuals was population 22 and the population with the lowest was population $24(N m=6.6$ and $N m=3.2$, respectively). In contrast, in the SW side, the population with the highest number of migratory individuals was population 1 whereas the lowest number was found in population $12(\mathrm{Nm}=3.8$ and $\mathrm{Nm}=1.2$, respectively). A similar pattern was found in the evaluation of recent gene flow (i.e. BayesAss). All migration rates were smaller than one migrant per generation, although higher rates were found in populations at both sides of the highway (i.e. population 15 at NE side and population 7 at SW side, forming small clusters (Table S4). Ancient gene flow showed a similar pattern (i.e. Migrate), with populations with high and small migration values at both sides of the highway (Table S5). Only two populations (pop 15 and 3) showed high values of gene flow with both approaches.

The best GLS model or explaining differences in $F_{S T}$ values contained as predictors the Euclidean distance between patches or the highway side (Table 2). Therefore, $F_{S T}$ was higher when geographic distance among populations was higher or when populations belonged to different highway side. However, these differences should be considered with caution, due to the small reduction in AIC values when this last variable was included in the model (Table 2).

\section{Genetic structure and association with environmental variables}

Bayesian analyses suggested different number of genetic clusters $(K)$. Namely, the Evanno method suggest $K=4$ as the most plausible value. MedMedK and MedMeaK support a $K=7$ and MaxMedK and MaxMeaK indcated that $K=8$ (Fig 2). These differences suggest the existence of some internal substructure within the main 4 clusters. This heterogeneity in the number of clusters is the result of internal divisions suggesting the existence of nested structures. For instance, some of the clusters proposed by $K=4$ split into different clusters with $K=7$ or $K=8$. The cluster that groups populations 16 to 24 are divided into three different clusters in $K=7$ or 8 (populations 17,18 and 19 in one cluster, population 24 in by itself, and the other populations in another cluster). In contrast, sPCA showed a global structure ( $p$-value $=0.01)$ but no a fine scale pattern ( $p$-value $>0.05$; Fig. 3C, 3D). This was surveyed in the map of genetic clines (Fig. 3A), 
315

316

317

318

319

320

321

322

323

324

325

326

327

328

329

330

331

332

333

334

335

336

337

338

339

340

341

342

343

344

345

346

347

348

349

350

351

352

353

354

where individual scores were similar in all the study area, except in populations 3, 15-19 and 1112, and in the eigenvalues (Fig. 3B), where only it is remarked one among the positive values (global structure). In the case of the linear models, we found that some genetic descriptors, such as allelic richness (estimate $=0.001 ; p$-value $<0.01$ ) and expected heterozygosis (estimate $=0.01 ; p$ value $=0.04$ ), were positively related to the population density of the patch (Figure 4). We did not find any other relation with the rest of genetic parameters and environmental variables.

\section{Discussion}

The fragmentation paradigm has been mainly constructed by surveying some demographic and/or fitness estimates of individuals, populations or communities (Fahrig, 2003).

Unfortunately, fragmentation effects remain uncharacterised for most habitats and, moreover, its consequences (both negative and positive) for many species remain unknown (Fahrig, 2003;

Fahrig, 2019). This emerging paradigm needs the explicit consideration of the so-called genetic perspective to include not only current ecological processes but also evolution, combining fragmentation with other factors that could shape the genetic population structure (Aguilar et al., 2008; Matesanz et al., 2017). In this context, linear infrastructure has emerged as powerful fragmentation driver, inducing negative effects on genetic diversity and fluxes (Balkenhol \& Waits, 2009; Holderegger \& Giulio, 2010). Nonetheless, most of studies have focused on animals, especially from a genetic perspective (Balkenhol \& Waits, 2009; Holderegger \& Giulio, 2010). In this context, we evaluated the effects of fragmentation and the barrier effect of a highway in a gypsum soil plant specialist, Lepidium subulatum, considering not only the landscape structure but also other indicators of ecological quality of the habitat remnants together with some population features. It have been emphasised that soil specialists could have reduced evolutionary potential because specialisation could constitute an evolutionary dead end if environmental conditions shift (Anacker et al., 2011; Bieger, Rajakaruna \& Harrison, 2014). Nonetheless, recent evidences showed that population genetics of some gypsum specialists suggested a significant resilience and plasticity to adverse conditions (Martínez-Nieto et al., 2012; García-Fernández et al., 2018; Matesanz et al., 2018; Cohen, 2019). In this sense, Lepidium subulatum, which shows an outstanding ecological and genetic variability at different spatio-temporal scales, is a valuable plant model to study not only fragmentation but also its response to other global change drivers (Gómez-Fernández, Alcocer \& Matesanz, 2016). Even more, this species showed minimal local adaptation, being its populations' phenotypic differentiation and local adjustment amounted to phenotypic plasticity (Matesanz et al., 2020).

\section{Path genetic differentiation}

Populations of L. subulatum presented significant variation in genetic diversity, gene flow and structure (e.g. allelic richness and heterozygosity). This variation might be associated with selective drivers that constrain the populations, but also to neutral processes that may foster different levels of genetic diversity in the remnant populations, including biological, demographic and ecological features. Although selective and neutral processes are acting, $L$. 
355

356

357

358

359

360

361

362

363

364

365

366

367

368

369

370

371

372

373

374

375

376

377

378

379

380

381

382

383

384

385

386

387

388

389

390

391

392

393

394

subulatum should sustain levels of genetic diversity that are enough to maintain plastic responses to different environmental conditions (Matesanz et al., 2020). L subulatum is a generalist entomophilous and primarily self-incompatible species (Loveless \& Hamrick, 1984; GómezFernández, Alcocer \& Matesanz, 2016), with an important and long-standing presence in the soil seed bank (Caballero et al., 2005) and significant plant recruitment under field conditions (Escudero et al., 2000). These factors may support the relatively high levels of genetic diversity, even with the presence of selective forces and demographic or stochastic events which could tend to minimise this variation.

We detected evidences suggesting recent bottlenecks or founder events. Perhaps, due to these, some patches presented a particular concern due to the existence of local moderate $F$ inbreeding coefficients. This probably is due to crossing with close relatives within patches (dispersal is very inefficient, see Escudero et al., 2000), causing an increase of kinship and, therefore, inbreeding (Fischer, Hock \& Paschke, 2003). It is well known that inbreeding (or high kinship similarity) has a negative effect on population dynamics because it reduces the reproductive success of the species (Jolivet, Rogge \& Degen, 2013; Hermansen et al., 2015) and the frequency of heterozygosity, fixing more easily any deleterious alleles (Mattey \& Smiseth, 2015) which potentially decrease the adaptive ability of the species (Porcher \& Londe, 2016). However, as the loci number is low, these $F$ inbreeding coefficient values could be due to presence of null alleles.

\section{Genetic differentiation and migrants: Highway barrier}

Our most remarkable result is the weak effects of the highway on the genetic structure (allelic richness, heterozygosity, genetic differentiation, gene flow parameters) of this species. This type of infrastructure could act as a barrier but could also improve the gene flow between the both sides due to the movement of vehicles or animals, with principal or auxiliary roads acting as dispersal pathways (Schmidt, 1989; Tikka, Högmander \& Koski, 2001). Other potential causes that might explain the reduced effect of the highway could be related to the relatively small scale of the study (along $10 \mathrm{~km}$ of the motorway), the molecular tool employed (i.e. neutral markers, Balkenhol, Waits \& Dezanni, 2009) and the fact that it would be necessary additional generations to verify any genomic signal in the populations (see Eugenio et al., 2012). It is worthwhile to note that some populations on the SW side of the study site might be suffering a potential barrier effect, as showed by the relatively high $F_{S T}$ values between populations pairs (Table 1 and S1). Therefore, it would be interesting to perform a detailed study to separate the possible existence of genetic differentiation derived from selection or demographic dynamics that could suggest potential local extinction risks.

Remnant populations retained most of the genetic diversity of the species in the area, which has been demonstrated as essential to maintain the capabilities of the species to cope with the uniqueness of this habitat (Matesanz et al., 2020). The presence of certain levels of gene flow (present and ancient) and the moderate $F_{S T}$ values could indicate that there is not a deficit in heterozygotes in the remnants. The exchange of genetic material could be mainly favoured by 
395

396

397

398

399

400

401

402

403

404

405

406

407

408

409

410

411

412

413

414

415

416

417

418

419

420

421

422

423

424

425

426

427

428

429

430

431

432

433

434

some pollination features (Aguilar et al., 2008; Matesanz et al., 2015; Gómez-Fernández, Alcocer \& Matesanz, 2016) and by the cattle herds and their movements. The existence of dense soil seed banks (Eugenio et al. 2012) can also ameliorate the genetic differentiation among populations. On the other hand, in some patchy populations, there is a high number of private alleles. This genetic parameter is related to the amount of genetic flow among patches (Slatkin \& Barton, 1989), and could indicate a reduction of genetic flow among populations, or at least, suggests some particular population dynamics in those patches. The number of private alleles is higher than those obtained in the other study of the species (Gómez-Fernández, Alcocer \& Matesanz, 2016). This discrepancy could be due to differences in the study areas that favour or restrict genetic flow, for instance, the shape or the size of the gypsum habitat remnants.

\section{Genetic structure and association with environmental variables}

Estimates of the genetic structure differed slightly depending on the followed approach. We obtained $\mathrm{K}=4$ when using Bayesian analyses (i.e. STRUCTURE), while 20 neighbours were necessary to connect the network in the sPCA, although the global structure was also the most important. Nonetheless, both cases showed an important admixture of population of both sides of the highway. Consequently, the highway did not exert a significant barrier effect. This high level of admixture in the genetic clustering might be associated with the presence of different factors that foster the dispersal of the species and maintain the high levels of genetic diversity. Efficient seed dispersal among patches could be associated with the active presence of cattle or mainly stationary (or partially stationary) sheep herds within the area. Highways could work as a barrier but also improve plant dispersal, since vertebrates used roads to move, creating corridors (Suárez-Esteban, Delibes \& Frediani, 2013). In this sense, several studies have showed the role that herbivores plays in seed dispersal in gypsum specialists (Pueyo et al. 2008). Sheep seem to have a remarkable effect in the short and long-distance seed dispersal (Manzano \& Malo, 2006; García-Fernández et al. 2019), even when seeds do not have the appropriate surface structures (e.g. seed hooks; Bakker et al. 1996). Foraging dynamics could profoundly affect the structure of the whole landscape since sheep can graze remnants in an unpredictable pattern and occurs variably as a function of the season and palatable biomass.

Surprisingly, we found only marginally significant relationships between genetic parameters and the environmental or landscape variables. As it occurs with other edaphic specialists, L. subulatum only grows in gypsum soils and such specialisation probably acts as an almost binomial filter for the species; the species is excluded of non-gypsum soils but is very abundant in any adequate gypsum island (Palacio et al. 2007; Escudero et al. 2015). Nevertheless, only population density had a positive effect in the allelic richness and the expected heterozygosis, suggesting that patches with a higher number of individuals, independently of other soil or landscape conditions, show higher levels of genetic diversity. This, in accordance with controlled studies in common garden experiments, induces high levels of phenotypic plasticity, a necessity for facing stressful conditions (Matesanz et al. 2020). 
435

436

437

438

439

440

441

442

443

444

445

446

447

448

449

450

451

452

453

454

455

456

457

458

459

460

461

462

463

464

465

466

467

468

469

470

471

472

\section{Conclusions}

Fragmentation effects in this edaphic specialist seems to be negligible. Concurrent effect of a busy highway with agriculture-induced fragmentation appears insufficient to affect its genetic structure and viability. As described in other fragmented gypsum scenarios, biological features, demographic dynamics and population structure of these species seem a pre-requisite to allow them to evolve as soil specialists in edaphic island environments and to maintain their competitiveness with other species in such harsh conditions. Man-made fragmentation and exacerbation of this island-like landscapes do not seem a problem for the viability of the species. Phenotypic plasticity, together with a generalist pollination, an efficient dispersal mechanism combining short, dense accumulation of seeds in the vicinity of mothers and occasional longdistance dispersal by livestock, guarantee its persistence.

\section{Acknowledgments}

We are indebted to Carlos Diaz (URJC) for his support during field work and to Iñaki Mola for all his help during the ECONECT project.

\section{REFERENCES}

Adams RV, Burg TM. 2015. Gene Flow of a Forest-Dependent Bird across a Fragmented Landscape. PLoS ONE 10(11): e0140938.

Aguilar R, Quesada M, Ashworth L, Herrerías-Diego Y, Lobo J. 2008. Genetic consequences of habitat fragmentation in plant populations: susceptible signal in plant traits and methodological approaches. Molecular Ecology 17: 5177-5188 DOI: 10.1111/j.1365294X.2008.03971.x

Ament R, Clevenger AP, Yu O, Hardy A. 2008. An Assessment of Road Impacts on Wildlife Populations in U.S. National Parks. Environmental Management 42: 480-496 DOI: 10.1007/s00267-008-9112-8

Anacker BL, Whittall JB, Goldberg EE, Harrison SP. 2011. Origins and consequences of serpentine endemism in the California flora. Evolution 65(2): 365-376 DOI: $10.1111 / \mathrm{j} .1558$ 5646.2010.01114.x

Arenas JM, Escudero A, Magro S, Balaguer L, Casado MA. 2015. Woody colonization of road embarkments: A large spatial scale survey in central Spain. Landscape and Urban Planning 141: 52-58 DOI: 10.1016/j.landurbplan.2015.04.009

Arenas JM, Lázaro-Lobo A, Mola I, Escudero A, Casado MA. 2017. The influence of site factors and proximity of adjacent vegetation on tree regeneration into roadslopes. Ecological Engineering 101: 120-129 DOI: 10.1016/j.ecoleng.2017.01.007

Bakker JP, Poschlod P, Strykstra RJ, Bekker RM, Thompson K. 1996. Seed banks and seed dispersal: important topics in restoration ecology. Acta Botanica Neerlandica 45(4): 461490 DOI: $10.1111 /$ j.1438-8677.1996.tb00806.x 
473

474

475

476

477

478

479

480

481

482

483

484

485

486

487

488

489

490

491

492

493

494

495

496

497

498

499

500

501

502

503

504

505

506

507

508

509

510

511

Balkenhol N, Waits LP. 2009. Molecular road ecology: exploring the potential of genetics for investigating transportation impacts on wildlife. Molecular Ecology 18: 4151-4164 DOI: 10.1111/j.1365-294X.2009.04322.x

Balkenhol N, Waits LP, Dezanni J. 2009. Statistical approaches in landscape genetics: an evaluation of methods for linking landscape and genetic data. Ecography 32: 818-830 DOI: $10.1111 / \mathrm{j} .1600-0587.2009 .05807 . x$

Bascompte J, Possingham H, Roughgarden J. 2002. Patchy Populations in Stochastic Environments: Critical Number of Patches for Persistence. The American Naturalist 159(2): 128-137 DOI: 10.1086/324793

Beerli P. 2009. How to use MIGRATE or why Markov chain Monte Carlo programs difficult to use? In: Bertonelle G, Bruford MW, Hauffe HC, Rizzoli A, Vernesi C, eds. Population Genetics for Animal Conservation. Cambridge: Cambridge University Press, 42-79.

Benítez-López A, Alkemade R, Verweij PA. 2010. The impacts of roads and other infrastructure on mammal and populations: A meta-analysis. Biological Conservation 143: 1307-1316 DOI: $10.1016 /$ j.biocon.2010.02.009

Bieger A, Rajakaruna N, Harrison S. 2014. Little evidence for local adaptation to soils or microclimate in the post-fire recruitment of three Californian shrubs. Plant Ecology \& Diversity 7(3): 411-420 DOI: 10.1080/17550874.2012.701670

Boarman WI, Sazaki M. 2006. A highway's road-effect zone for desert tortoises (Gopherus agassizii). Journal of Arid Environments 65: 94-101 DOI: 10.1016/j.jaridenv.2005.06.020

Boletín Oficial del Estado. 2016. Orden FOM/273/2016, de 19 de febrero, por la que se aprueba la Norma 3.1-IC Trazado, de la Instrucción de Carreteras. BOE 55 (4 de marzo de 2016): $17657-17893$

Boulinier T, Nichols JD, Hines JE, Sauer JR, Flatcher CH, Pollock KH. 2001. Forest fragmentation and bird community dynamics: inference at regional scales. Ecology, 82(4), 1159-1169 DOI: 10.1890/0012-9658(2001)082[1159:FFABCD]2.0.CO;2

Caballero I, Olano JM, Luzuriaga AL, Escudero A. 2005. Spatial coherence between seasonal seed banks in a semi-arid gypsum community: density changes but structure does not. Seed Science Research 15(2): 153-160 DOI: 10.1079/SSR2005206

Chapuis MP, Estoup A. 2007. Micosatellite null alleles and estimation of population differentiation. Molecular Biology and Evolution 24(3): 621-631.

Chapuis MP, Lecoq M, Michalakis Y, Loiseau A, Sword A, Piry S, Estoup A. 2008. Do outbreaks affect genetic population structure? A worldwide survey in Locusta migratoria, a pest plagued by microsatellite null alleles. Molecular Ecology 17(16). 3640-3653.

Clauzel C, Xiqing D, Gongsheng W, Giraudoux P, Li L. 2015. Assessing the impact road developments on connectivity across multiple scales: Application to Yunnan snub-nosed monkey conservation. Biological Conservation 192: 207-217 DOI:

10.1016/j.biocon.2015.09.029

Peer] reviewing PDF | (2020:06:50064:2:0:NEW 18 Nov 2020) 
512 Coffin AW. 2007. From roadkill to road ecology: A review of the ecological effects of roads.

513 Journal of Transport Geography 15: 396-406 DOI: 10.1016/j.jtrangeo.2006.11.006

514 Cornuet JM, Luikart G. 1996a. Description and Power Analysis of Genetic Differentiation

515 between Populations. Genetics 163: 367-374 DOI: 10.1371/journal.pone.0042649

516 Cornuet JM, Luikart G. 1996b. Description and Power Analysis of Two Tests of Detecting

517 Recent Population Bottlenecks From Allele Frequency Data. Genetics 144: 2001-2014

518 Cohen JI. 2019. The conservation genomics of the endangered distylous gypsophyle Oreocarya

519 crassipes (Boraginaceae). Conservation Genetics 20: 1315-1328.

520 Diario Oficial de las Comunidades Europeas. (1992). Directiva 92/43/CEE del Consejo de 21 de

521 mayo de 1992 relativa a la conservación de los hábitats naturales y de la fauna y flora

522 silvestres. DOUE L: 206-250.

523 Environmental Systems Research Institute (ESRI). 2012. ArcGIS Release 10.1. Redlands, CA.

524 Escudero A, Iriondo JM, Olano JM, Rubio A, Somolinos R. 2000. Factors affecting the

525 establishment of a gypsophyte: The case of Lepidium subulatum (Brassicaceae). American

526 Journal of Botany 87: 861-871.

527 Escudero A, Palacio S, Maestre FT, Luzuriaga AL. 2015. Plant life on gypsum: a review of its

528 multiple facets. Biological Reviews 90: 1-18 DOI: 10.1111/brv.12092

529 Eugenio M, Olano JM, Ferrandis P, Martínez-Duro E, Escudero A. 2012. Population structure of

530 two dominant gypsophyite shrubs through a secondary plant succession. Journal of Arid

531 Environments 76: 30-35 DOI: 10.1016/j.jaridenv.2011.07.001

532

533

534

535

536

537

538

539

540

541

542

543

544

545

546

547

548

549

Evanno G, Regnaut S, Goudet J. 2005. Detecting the number of clusters of individuals using the software STRUCTURE: A simulation study. Molecular Ecology 14(8): 2611-2620 DOI: 10.1111/j.1365-294X.2005.02553.x

Fahrig L. 2002. Effect of habitat fragmentation on the extinction threshold: a synthesis.

Ecological Applications 12(2): 346-353 DOI: 10.1890/10510761(2002)012[0346:EOHFOT]2.0.CO;2

Fahrig L. 2003. Effects of Habitat Fragmentation on Biodiversity. Annual Review of Ecology, Evolution, and Systematics 34: 487-515 DOI: 10.1146/annurev.ecolsys.34.011802.132419

Fahrig L. 2019. Habitat fragmentation: A long and tangled tale. Global Ecology and Biogeohraphy 28(1): 33-41 DOI: 10.1111/geb.12839

Fischer M, Hock M, Paschke M. 2003. Low genetic variation reduces cross-compatibility and offspring fitness in population of a narrow endemic plant with a self-incompatibility system. Conservation Genetics 4: 325-336 DOI: 10.1023/A:1024051129024

Forman RTT, Alexander LE. 1998. Roads and Their Major Ecological Effects. Annual Reviews of Ecology, Evolution and Systematics 29: 207-231 DOI: 10.1146/annurev.ecolsys.29.1.207

García-Fernández A, Manzano P, Seoane J, Azcárate FM, Iriondo JM, Peco B. 2019. Herbivore corridors sustain genetic footprint in plant populations: a case for Spanish drove roads. PeerJ 7: e7311. 
550 Gelman F, Binstock R, Halicz L. 2012. Application of the Walkley-Black titration for the 551 organic carbon quantification in organic rich sedimentary rocks. Fuel 96: 608-610 DOI: $552 \quad$ 10.1016/j.fuel.2011.12.053

553 Gómez-Fernández A, Alcocer I, Matesanz S. 2016. Does higher connectivity lead to higher 554 genetic diversity? Effects of habitat fragmentation on genetic variation and population 555 structure in a gypsophile. Conservation Genetics 17: 631-641 DOI: 10.1007/s10592-016$556 \quad 0811-\mathrm{z}$

557

558

559

560

561

562

563

564

565

566

567

568

569

570

571

572

573

574

575

576

577

578

579

580

581

582

583

584

585

586

587

588
Hermansen TD, Roberts DG, Toben M, Michinton TE, Ayre DJ. 2015. Small Urban Stands of the Mangrove Avicennia marina are Genetically Diverse but Experience Elevated Inbreeding. Estuarine, Coastal and Shelf Science 38: 1898-1907 DOI: 10.1007/s12237-015-9955-1

Hernández Bermejo JE, Clemente M. 1993. Lepidium L. in Castroviejo, S.; Gómez, C.; Morales, R.; Nieto, G.; Rico E.; Talavera, S. (eds). Flora Ibérica 4: 311-327

Holderegger R, Di Giulio M. 2010. The genetic effects of road: A review of empirical evidence. Basic and Applied Ecology 11: 522-531 DOI: 10.1016/j.baae.2010.06.006

Janes JK, Miller JM, Dupuis JR, Malefant RM, Gorrell JC, Cullingham CI, Andrew RL. 2017. The K=2 conundrum. Molecular Ecology 26(14): 3594-3602.

Jolivet C, Rogge M, Degen B. 2013. Molecular and quantitative signatures of biparental inbreeding depression in the self-compatible tree species Prunus avium. Heredity 110: 439448 DOI: $10.1038 /$ hdy.2012.103

Jombart T. 2008. adegenet: a R package for the multivariante analysis of genetic markers. Bioinformatics 24: 1403-1405 DOI: 10.1093/bioinformatics/btn129

Jombart T, Ahmed I. 2011. adegenet 1.3-1: new tools for the analysis of genome-wide SNP data. Bioinformatics 27(21): 3070-3071 DOI: 10.1093/bioinformatics/btr521

Kalinowski ST. 2005. HP-Rare: A computer program for performing rarefaction on measures of allelic diversity. Molecular Ecology Notes 5: 187-189 DOI: 10.1111/j.14718286.2004.00845.x

Karlson M, Mörtberg U, Balfors B. 2014. Road ecology in environmental impact assessment. Environmental Impact Assessment Review 48: 10-19 DOI: 10.1016/j.eiar.2014.04.002

Kierepka EM, Latch EK. 2015. Fine-scale landscape genetics of the American badger (Taxidea taxus): disentangling landscape effects and sampling artifacts in a poorly understood species. Heredity 116: 33-43 DOI: 10.1038/hdy.2015.67

Kuiters AT, Huiskes HPJ. 2010. Potential of endozoochorous seed dispersal by sheep in calcareous grasslands: correlations with seed traits. Applied Vegetation Science 13: 163-172 DOI: 10.1111/j.1654-109X.2009.01058.x

Li Y L, Liu JX. 2018. StructureSelector: a web-based software to select and visualize the optimal number of clusters using multiple methods. Molecular Ecology Resources 18(1): 176-177 DOI: $10.1111 / 1755-0998.12719$

Loveless MD, Hamrick JL. 1984. Ecological determinants of genetic structure in plant populations. Annual Review of Ecology, Evolution, and Systematics 15: 65-95

Peer] reviewing PDF | (2020:06:50064:2:0:NEW 18 Nov 2020) 
589

590

591

592

593

594

595

596

597

598

599

600

601

602

603

604

605

606

607

608

609

610

611

612

613

614

615

616

617

618

619

620

621

622

623

624

625

626

627

Maestre FT, Puche MD. 2009. Indices based on surface indicators predict soil functioning in Mediterranean semi-arid steppes. Applied Soil Ecology 41: 342-350 DOI: 10.1016/j.apsoil.2008.12.007

Manel S, Holderegger R. 2013. Ten years of landscape genetics. Trends in Ecology \& Evolution 28(10): 614-621 DOI: 10.1016/j.tree.2013.05.012

Manzano P, Malo EJ. 2006. Extreme long-distance seed dispersal via sheep. Frontiers in Ecology and the Environtment 4(5): 244-248 DOI: 10.1890/15409295(2006)004[0244:ELSDVS]2.0.CO;2

Martínez-Hernández F, Pérez-García FJ, Garrido-Becerra JA, Mendoza-Fernández AJ, MedinaCazorla JM, Martínez-Nieto MI, Merlo Calvente ME, Mota-Poveda JF. 2011. The distribution of the Iberian gypsophilous flora as a criterion for conservation policy. Biodiversity and Conservation 20:1353-1364 DOI: 10.1007/s10531-011-0031-2

Martínez-Nieto MI, Merlo ME, Mota JF, Salmerón-Sánchez E, Segarra-Moragues JG. 2012. Microsatellite Loci in the Gypsophite Lepidium subulatum (Brassicaceae), and Transferability to Other Lepidieae. International Journal of Molecular Science 13: 1186111869.

Matesanz S, Escudero A, Valladares F. 2009. Impact of three global change drivers on a Mediterranean shrub. Ecology 90(9): 2609-2621 DOI: 10.1890/08-1558.1

Matesanz S, García-Fernández A, Limón-Yelmo A, Gómez-Fernández A, Escudero A. 2018. Comparative landscape genetics of a gypsum specialist with naturally-patchy distributions reveal their resilience to anthropogenic fragmentation. Perspectives in Plant Ecology, Evolution and Systematics 34: 1-9 DOI: 10.1016/j.ppees.2018.07.001

Matesanz S, Gómez-Fernández A, Alcocer I, Escudero A. 2015. Fragment size does not matter when you are well connected: effects of fragmentation on fitness of coexisting gypsophiles. Plant Biology 17(5): 1047-1056 DOI: 10.1111/plb.12329

Matesanz S, Ramos-Muñoz M, Moncalvillo B, Rubio-Teso ML, García de Dionisio SL, Romero J, Iriondo JM. 2020. Plasticity to drought and ecotypic differentiation in populations of a crop wild relative. AoB Plants 12(2): plaa006.

Matesanz S, Rubio-Teso ML, García-Fernández A, Escudero A. 2017. Habitat Fragmentation Differentially Affects Genetic Variation, Phenotypic Plasticity and Survival in Populations of a Gypsum Endemic. Frontiers in Plant Science 8: 843 DOI: 10.3389/fpls.2017.00843

Matesanz S, Ramos-Muñoz M, Blanco-Sánchez M, Escudero A. 2020. High differentiation in functional traits but similar phenotypic plasticity in populations of a soil specialist along a climatic gradient. Annals of Botany 125(6): 969-980 DOI: 10.1093/aob/mcaa020

Mota JF, Sola AJ, Jiménez-Sánchez ML, Pérez-García FJ, Merlo ME. 2004. Gypsicolous flora, conservation and restoration of the quarries in the southeast of the Iberian Peninsula. Biodiversity \& Conservation 13: 1797-1808 DOI: 10.1023/B:BIOC.0000035866.59091.e5 Mattey SN, Smiseth PT. 2015. Complex Effects of Inbreeding on Biparental Cooperation. The American Naturalist 185(1): 1-12 DOI: 10.1086/679067 
628 Nogués S, Cabarga-Varona A. 2014. Modelling land use changes for landscape connectivity: the 629 role of plantation forestry and highways. Journal for Nature Conservation 22(6): 504-515 630 DOI: 10.1016/j.jnc.2014.08.004

631 Olano JM, Caballero I, Escudero A. 2012. Soil seed bank recovery occurs more rapidly than 632 expected in semi-arid Mediterranean gypsum vegetation. Annals of Botany 109: 299-307.

633 Palacio S, Escudero A, Monserrat-Martí G, Maestro M, Milla R, Albert MJ. 2007. Plants living on gypsum: beyond the specialist model. Annals of Botany 99(2): 33-343 DOI: 10.1093/aob/mcl263

Palacio S, Montserrat-Martí G. 2005. Bud Morphology and Shoot Growth Dynamics in Two Species of Mediterranean Sub-shrubs Co-existing in Gypsum Outcrops. Annanls of Botany 95: 949-958 DOI: 10.1093/aob/mci110

Peakall R, Smouse PE. 2006. GENALEX 6: genetic analysis in Excel. Population genetic software for teaching and research. Molecular Ecology Notes 6: 288-295 DOI: 10.1111/j.1471-8286.2005.01155.x

Pinheiro J, Bates D, DebRoy S, Sarkar D, R Core Team. 2018._nmle: Linear and Nonlinear Mixed Effects Models_. R package version 3.1-137: https://CRAN.Rproject.org $/$ package $=$ nmle

Pope N. 2019. cCorMLPE: A correlation structure for symetric relational data. $R$ package version 0.0.2: https://CRAN.R-project.org/package $=\mathrm{cCorMLPE}$

Porcher E, Lande R. 2016. Inbreeding depression under mixed outcrossing, self-fertilization and sib-mating. BMC Evolutionay Biololgy 16: 105-118 DOI: 10.1186/s12862-016-0668-2

Puechmaille SJ. 2016. The program STRUCTURE does not reliably recover the correct population structure when samplings is uneven: subsampling and new estimators alleviate the problem. Molecular Ecology Resources 16(3): 608-627 DOI: 10.1111/1755-0998.12512

Pueyo Y, Alados CL, Barrantes O, Komac B, Rietker M. 2008. Differences in gypsum plant communities associated with habitat fragmentation and livestock grazing. Ecological Applications 18(4): 954-964 DOI: 10.1890/07-1770.1

R Core Team. 2016. R: A language and environment for statistical computing. R Foundation for Statistical Computing, Vienna, Austria. https://www.R-project.org/

Raymond M, Rousset F. 1995. GENEPOP (version 1.2): population genetics software for exact tests and ecumenicism. Journal of Heredity 86: 248-249

Romão RL, Escudero A. 2005. Gypsum physical soil crusts and the existence of gypsophytes in semi-arid central Spain. Plant Ecology 181: 127-137 DOI: 10.1007/s11258-005-5321-x

Rousset F. 2008. Genepop'007: a complete reimplementation of the Genepop software for Windows and Linux. Molecular Ecology Resources 8: 103-106.

Schmidt W. 1989. Plant dispersal by motor cars. Vegetatio 80 : 147-152 DOI: 10.1007/BF00048038

Segelbacher G, Cushman SA, Epperson BK, Fortin M, Francois O, Hardy OJ, Holderegger R, Taberlet, P, Waits LP, Manel S. 2010. Applications of landscape genetics in conservation 
667

668

669

670

671

672

673

674

675

676

677

678

679

680

681

682

683

684

685

686

687

688

689

690

691 biology: concepts and challenges. Conservation Genetics 11: 375-385 DOI: 10.1007/s10592009-0044-5

Slatkin M. 1993. Isolation by Distance in Equilibrium and Non-Equilibrium Populations. Evolution 47(1): 264-279 DOI: 10.1111/j.1558-5646.1993.tb01215.x

Slatkin M, Barton NH. 1989. A Comparison of Three Indirect Methods for Estimating Average Level of Gene Flow. Evolution 43(7): 1349-1368 DOI: 10.1111/j.1558-5646.1989.tb02587.x

Suárez-Esteban A, Delibes M, Frediani JM. 2013. Barriers or corridors? The overlooked role of unpaved roads in endozoochorous seed dispersal. Journal of Applied Ecology 50: 767-774.

Suni SS, Witheley AR. 2015. Genetic structure of a montane perennial plant: the influence of landscape and flowering phenology. Conservation Genetics 16: 1431-1442 DOI: 10.1007/s10592-015-0751-z

Tikka PM, Högmander H, Koski PS. 2001. Road and railway verges serve as dispersal corridors for grassland plants. Landscape Ecology 16: 659-666

Tremlová K, Munzbergová Z. 2007. Importance of species traits for species distribution in fragmented landscapes. Ecology 88(4): 965-977 DOI: 10.1890/06-0924

Van Oosterhour C, Hutchinson WF, Wills DPM, Shipley P. 2004. MICRO-CHECKER: software for identifying and correcting genotyping errors in microsatellite data. Molecular Ecology Resources 4(3): 535-538.

Wilson GA, Rannala B. 2003. Bayesian Inference of Recent Migration Rates Using Multilocus Genotypes. Genetics 163(3):1171-1191.

Zane L, Bargelloni B, Patarnello T. 2002. Strategies for microsatellite isolation: a review. Molecular Ecology 11: 1-16 DOI: 10.1046/j.0962-1083.2001.01418.x

Zhou J, Xiao N, Liu L, Li Q. 2016. A weighted aggregation and closeness approach to measuring the compactness of landscape with multiples parts. Ecological Indicators 64: 158-170 DOI: 10.1016/j.ecolind.2015.12.022 


\section{Table $\mathbf{1}$ (on next page)}

Average values of genetic parameters of the study area and the both sides of the A-3 highway.

Genetic parameters were allelic richness, private alleles number, expected and observed heterozygosity $\left(H_{E}\right.$ and $H_{O}$, respectively), inbreeding coefficient $(F)$ and migratory individuals number $(\mathrm{Nm})$. 


\begin{tabular}{lllll}
\hline & & $\begin{array}{l}\text { Total of } \\
\text { populations }\end{array}$ & NE side & SW side \\
\hline Allelic & Average & 7.282 & 8.115 & 7.542 \\
Richness & SD & 1.267 & 1.037 & 1.450 \\
Rarefied & Average & 4.914 & 4.751 & 5.078 \\
Allelic & SD & 1.070 & 0.212 & 1.514 \\
Richness & & & & \\
Private & Total & 35 & 13 & 22 \\
Alleles & & & & \\
$\boldsymbol{H}_{\mathbf{e}}$ & Average & 0.758 & 0.784 & 0.732 \\
& SD & 0.049 & 0.025 & 0.054 \\
$\boldsymbol{H}_{\mathbf{0}}$ & Average & 0.650 & 0.673 & 0.626 \\
$\boldsymbol{F}$ & SD & 0.073 & 0.054 & 0.082 \\
& Average & 0.135 & 0.135 & 0.135 \\
$\mathbf{N m}$ & SD & 0.085 & 0.077 & 0.095 \\
& Average & 3.993 & 5.088 & 2.800 \\
\hline
\end{tabular}


Table 2 (on next page)

General Least Square models with AIC information values and $\triangle \mathrm{AIC}$. 


\begin{tabular}{lll}
\hline Model & AIC & $\Delta$ AIC \\
\hline Null & -1471.159 & 0 \\
$\boldsymbol{F}_{S T} \sim$ geographic distance & -1469.273 & -1.886 \\
$\boldsymbol{F}_{S T} \sim$ highway side & -1469.203 & -1.956 \\
$\boldsymbol{F}_{S T} \sim$ geographic distance + highway & -1467.317 & -3.842 \\
side & & \\
$\boldsymbol{F}_{S T} \sim$ geographic distance * highway & -1465.485 & -5.674 \\
side & & \\
\hline
\end{tabular}

1

2 


\section{Figure 1}

Situation of populations or patches in the study area.

In blue, the populations situated in the northeast (NE) A-3 highway side are stand for, and in red, the populations situated in the southwest (SW) of the highway. To make the figure, we used ArcGis using as a base layer at 2015 of the public map service IGN-PNOA wms ( https://pnoa.ign.es), and it does not have copyright (https://www.boe.es/boe/dias/2015/12/26/pdfs/BOE-A-2015-14129.pdf; Page 3, Article 4.1; 2015) 


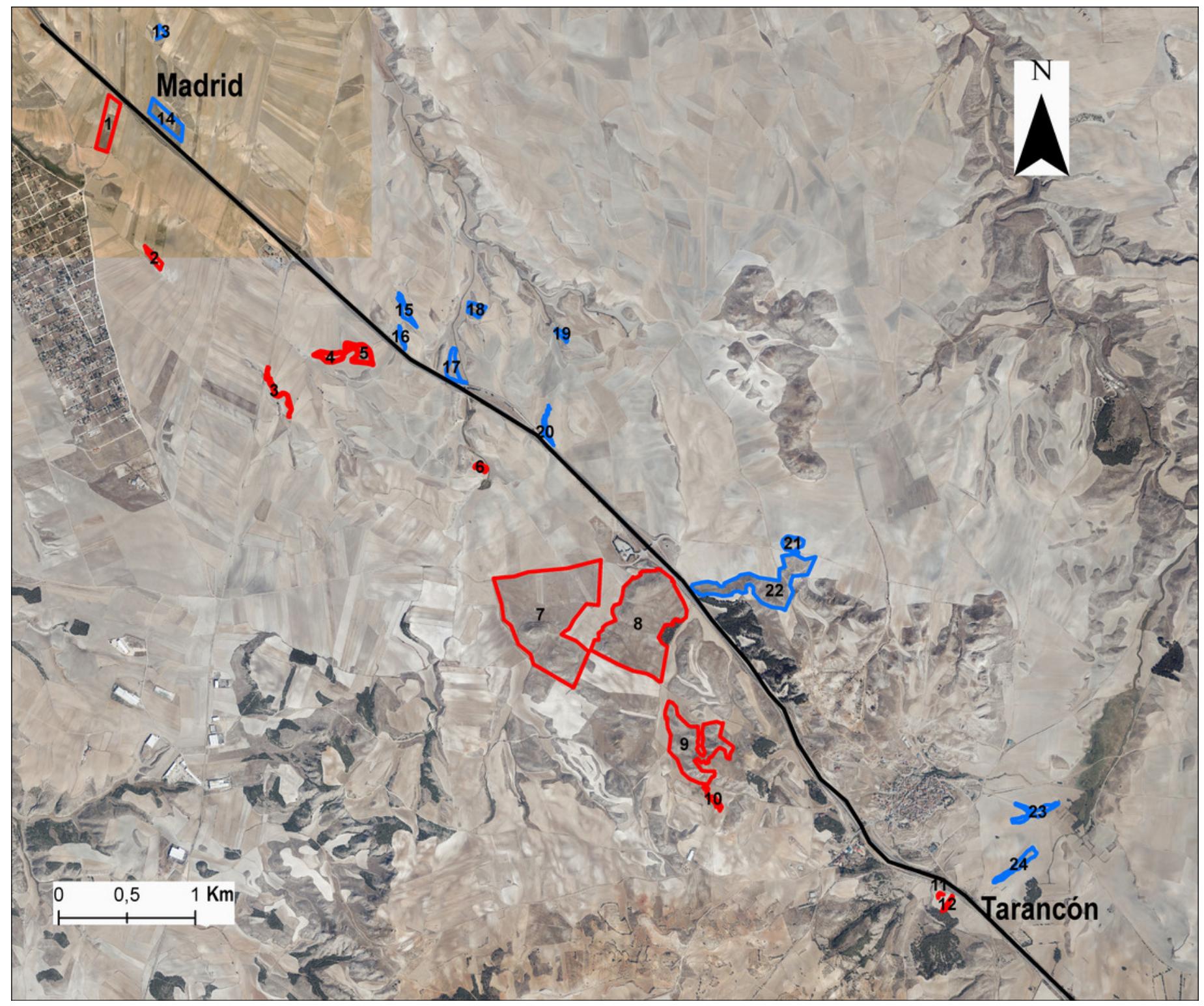


Figure 2

Genetic structure in the study area.

Probability of an individual belongs to a cluster when (A) $K=4$, (B) $K=7$ and (C) $K=8$ obtained by Structure; and (D) values of Delta $K$ in which $K=4$ is the most probable structure.

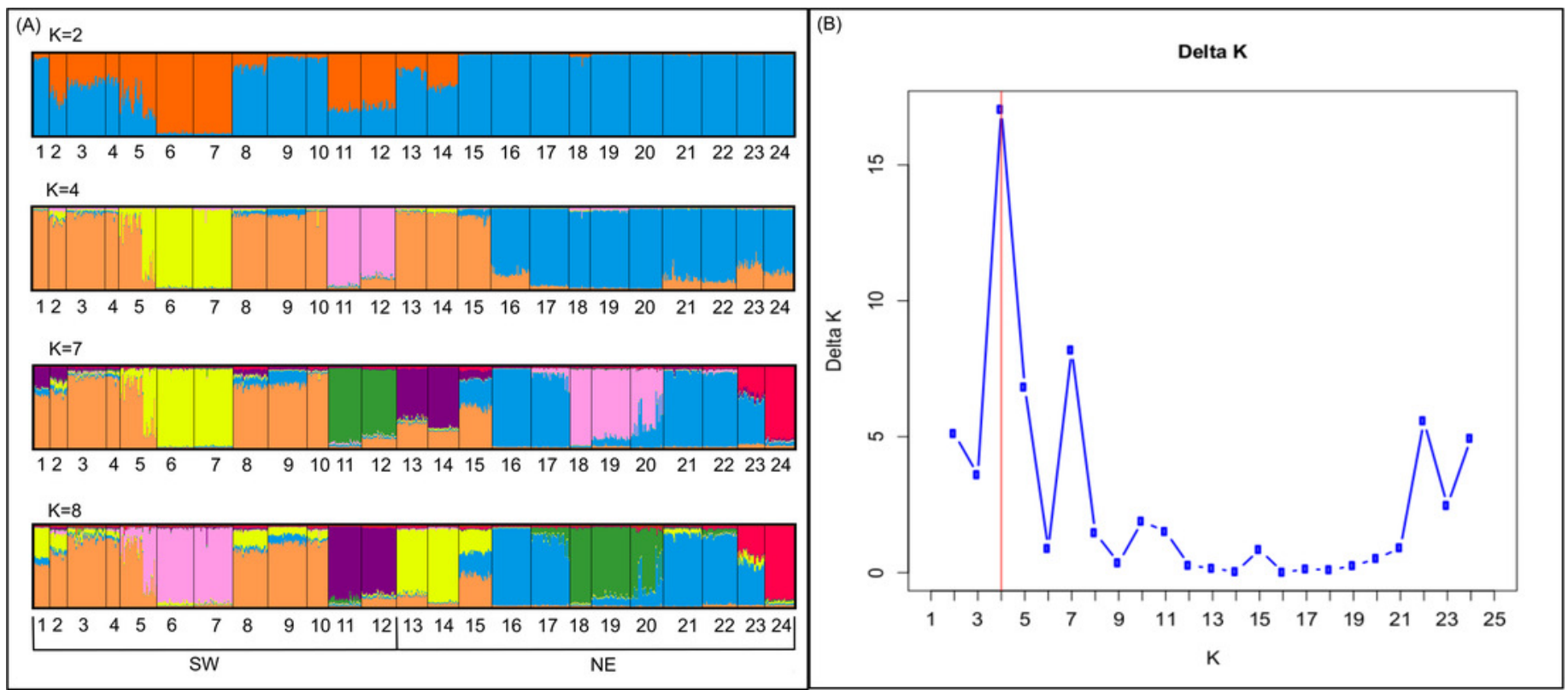


Figure 3

Spatial Principal Components Analysis.

(A) SPCA surface with the individual scores, population network (closest neighbor was 20) in black lines and the highway in grey line. Axes are in WGS84 coodinate system; (B) the eigenvalues of SPCA; (C) histogram of simulated values for the global structure and the observed value (black point and line); (D) histogram of simulated values for the local structure and the observed value (black point and line).

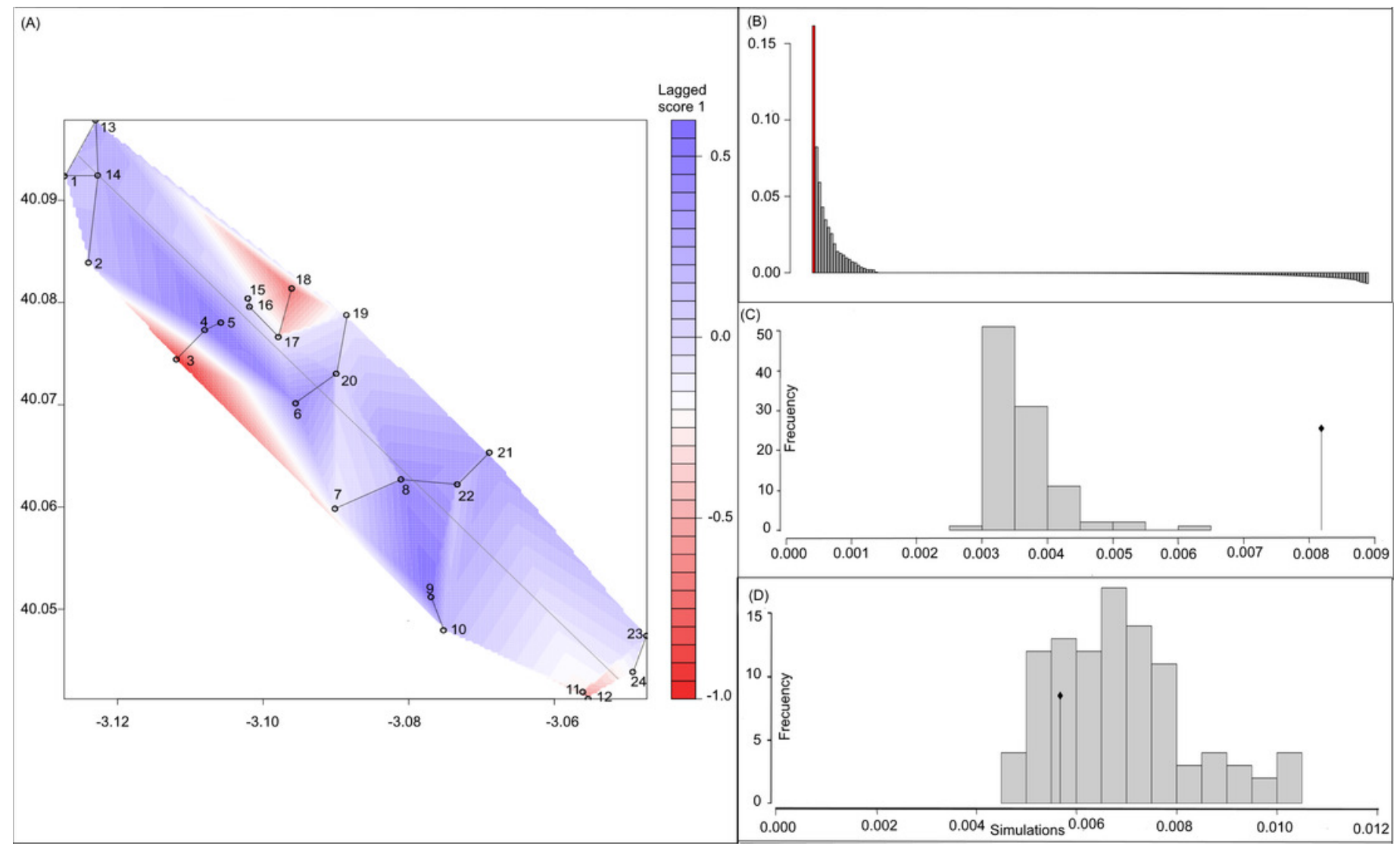


Figure 4

Relationship between (A) allelic richness and population density and (B) expected heterozygosity and population density.

Regression lines and p-value were obtained using GLMs. 

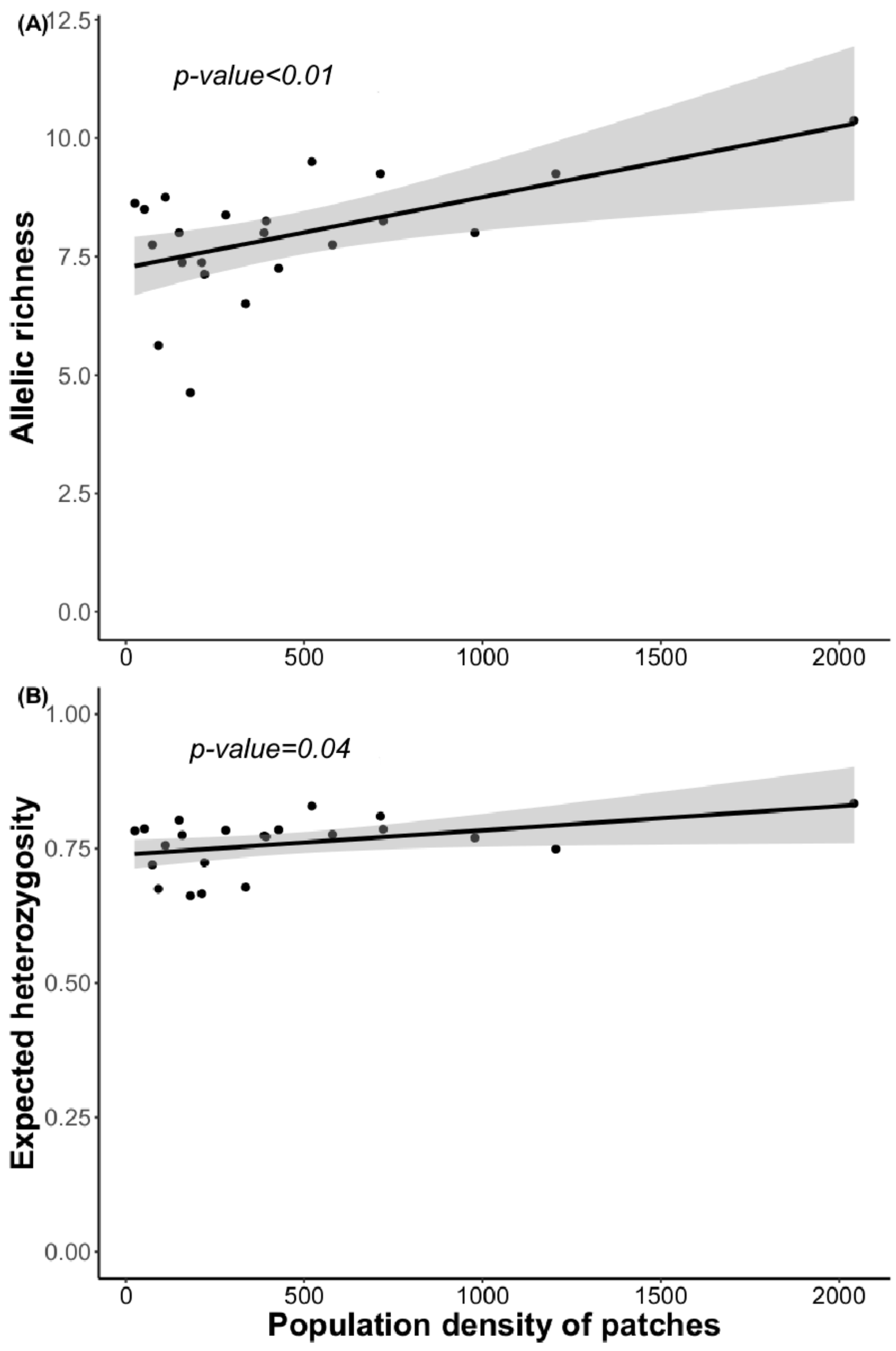